\title{
Exploration and Practice in the Artistic Design Software Teaching for Applied Talent Cultivation-mode \\ Min-min $\mathrm{GUO}^{1,{ }^{*}}$ and Li-ting $\mathrm{ZHOU}^{2}$
}

\author{
${ }^{1}$ Zaozhuang University, Zaozhuang, Shandong Province, 277100 China \\ ${ }^{2}$ Shandong Youth University of Political Science, Jinan, Shandong Province, 250103 \\ China \\ ${ }^{*}$ Corresponding author
}

Keywords: Applied talent, Design software, Teaching practice, Design expression.

\begin{abstract}
Propelling with the reform of applied undergraduate teaching in non-military colleges and universities, innovation for traditional artistic design projects and teaching system is vital. Combined with carrying out the reform of applied undergraduate teaching mode, we analyzed the teaching status of design software curriculum, which is the foundation of artistic design projects. In return, we derived an innovated and pointed teaching program for artistic design teaching practice.
\end{abstract}

\section{Introduction}

As one of extraordinary art expression modes software has been introduced to artistic teaching system since 1980's [1]. With the exploration and development over the last decades, it has been rooted in all through the art teaching areas. As a result, a hot spot emerges combining the soft ware with art teaching exploration [2]. Furthermore, the reform of applied undergraduate teaching mode emphasized the reoccurrence of this topic, with which to modify the traditional art teaching programs and in return, to apply the new programs in a more efficient way to reach the new points eventually.

\section{Analysis of Design Software Teaching in the Traditional Mode}

The present art major related design software projects are mainly: Corel Draw, Photoshop, Illustrator, Pagemaker and other two-dimensional image processing software; 3Dmax, Autocad, Maya and other three-dimensional design software; Sound Forge, Sound System, Crpative Wave Studio, Premiere, Personal AVI Editor and other audio video post-processing software. Teaching of these soft wares is designed to focus on practice instead of idolatrizing in the technology. It emphasizes the designing consciousness in application of design software. However, due to the specialty of the general culture and mode of thinking of art students, the teaching of design software failed to attain the expected result.

Take the environmental design in our college as an example: the software projects are composed of $3 \mathrm{dmax}$, Photoshop and Autocad. As a core subject, $3 \mathrm{dmax}$ has been opened to the second term of sophomore and the first term of junior, which amount to 120 hours in total. Unfortunately, there is no enough time for the teachers to guide the students in any single advanced commend. In addition, the art students' ability in theoretical learning is limited. Based on the current situations listed above, the teaching goals of advanced and complicated software, such as 3 dmax have been resistant. On the other hand, without considering the particularity of art subjects, no 
difference has been emphasized on the teaching content and teaching methods between the basic computer application courses of art major and other subjects [3].

As a professional basic course, computer software course adopts the sectional type-teaching mode in most design colleges [4], which is consistent with the traditional professional basic courses. That is, software and professional courses are separate in practice. The sectional teaching model has its unique advantage for traditional art teaching, but shortcomings seem to be in design software teaching. Without the scientific and effective combination, software would be mistaken as a tool for the replacement of pencil and paper but not an alternative designing method. As a result, the works that is embedded the digital designing essence is rare.

When it comes to the evaluation system, the arts major software teaching, which featured with practicality and operability, requires to be carried out with the professional creation. Meantime, the traditional written tests or pure software operation examination obviously fail to meet the teaching requirement. The exam-oriented computer software education emphasizes too much on the technical operation but rarely on the oriented assessment mode of adjusting to professional design requirement. Or even when the major features been considered, the evaluation system is usually restricted by the objective conditions of examination time or mode. As a result, the evaluation would be accomplished compromisingly with lower standard. In a word, the personalized education of art design major would be restricted seriously without a reasonable examination evaluation system.

\section{Outstanding Ideas of Design Software Teaching Adapted to the Reform of Applied Undergraduate Teaching}

Teaching orientation will be definite by the following two aspects. Firstly, the teaching characteristics of art major emphasize on improving the design thoughts and creation ability of the cultivation objects. As a result, the computer software teaching places emphasis upon cultivating students' ability to use the computer and self-learning. Instead, teachers are expected to guide students with the cultivation of innovational thinking and learning interests. Secondly, the imbalance of regional development and national education input power leads to the great gap of students' basic quality level, which adds a lot of pressure to the teaching work. In order to mobilize students' enthusiasm of independent study, intuitionistic teaching techniques are preferred in teaching.

Computer software teaching of design major would be connected with the specialty of the major instead of traditional 'spoon-feeding' teaching method and examination evaluation system. And advocate for the interactive teaching mode of 'taking students as the main part', which pays attention to the development and guidance of students' autonomy consciousness.

It is recommended that software teaching to be specialized with major fields to plan and perform the teaching activity. The teaching emphasis may vary in different fields of the same major [5]. Take photoshop software as an example, graphic design students place emphasis on creative graphic ideas but image processing is preferred by the environmental art students. In a word, teaching activity performs with priority based on different demands of students would be the most efficient trend for the current college education.

The total amount of computer software technology knowledge is huge and been updated accordingly to the constant changes of information technology. It is not possible for the students to master all the softwares on class. In addition, computer 
software technology experiences a much faster update period than ever. As a result, it is extremely important to strengthen the independent learning ability of the students. From our experience, we tried to introduce professional project to students in class by analyzing the significance of software parameters in the accomplishment of project. We expect students to combine the theory with techniques in learning and apply in a flexible way as well.

\section{Teaching Practice in View of the New Applied Teaching-mode}

\section{Improving Curricular Systems through the Classifying Teaching Practice}

Given the individual shorts coming, we try to make it up by increasing class hours appropriately. We introduce classified software teaching protocols as well as level individual software teaching strategies. In detail, the software classification is based on the difficulty levels of software and frequency usage. Although students from design major need to master a lot of softwares, different majors basically has its own main designing software with the using frequency, difficulty degree and the major feature have been taken in consideration. Taking the photoshop and 3dmax as example, the whole progress has been divided into primary, medium and advanced periods which have been performed from grade one to three accordingly. So the learners can manipulate software vary solid and upgrade their professional designing as well.

In addition, considering the imbalanced basic computer theory that individuals have reached in middle school, the computer digital design theory optional courses have been carried out in primary schools. In which to enhance the students' understanding of computer graphics software and expand students' design ideas and also provide theoretical support for learning software operation better as well.

\section{Syncretize the Profession and Software Teaching}

Differ from the traditional sectional teaching, for software teaching, we introduced the combination of mixed teaching mode and professional courses in practice. Design software teaching has been added in the professional creation curriculum. Teaching plans, teaching syllabus and examination evaluating method are compiled and mutually finished by the teachers of two aspects participated in teaching. Software teaching has been conducted through the creation subjects. Problems that students encountered in practice would be solved immediately by using interactive teaching. In turn, individuals can devote themselves to the professional creative learning, and the teaching efficiency can be quickly improved as well.

In addition, students have extraordinarily appreciated this interactive teaching practice. More energetic interaction and wider opening of the class together with homework analysis after class accomplished the combination of software teaching and professional creation.

\section{Up-regulate the Practicability and Spice of the Complementary Teaching Materials}

The teaching material design should consider the students as the active main focus of practical creation and set aside the development space for students' learning. The composition of textbooks is recommended to involve to both classroom teaching and individual learning, in which will emphasize the affinity for students. Textbooks could provide plenty of materials related to design projects and are able to guide the students to apply to the practices. 
The integration of teaching materials should not only overcome the narrow tendency of subject-orientation, but also prevent the non-subject tendency towards the subject teaching materials. Both the longitudinal relation between grades and lateral relation between majors should be considered when teaching materials are collected. Given the development of digital techniques at present, the combination of literatures, radio as well as Internet are the most trend of the development of software teaching.

\section{Reform of the Examination Evaluation System Based on the Professional Courses}

We adopted the reform of mixed teaching procedure in the teaching process. As a result, the examination focused on the daily evaluation of learning process accordingly. From which, practical application ability is the main evaluation point. The final performance is obtained by the mutual evaluation of teachers participating in mixed teaching. The traditional theory written tests are as supplementary investigation projects, which only account for $20 \%$ of the performance proportion.

\section{Conclusion}

In conclusion, under the background of applied undergraduate teaching the design software teaching reform for art design major is a beneficial attempt for us in teaching practice. By grasping the subject major features accurately and analyzing the differences among art students, we have made many new adjustments on teaching content and teaching methods. Which seems to have been seamlessly integrated in the software teaching and professional creation. It is proved that design software is not only a course or a skill, but the experience method is also relevant to all the other courses. Our initial attempt on software teaching changes the traditional teaching organization form and teaching method. This forming constructive and discovery learning methods have greatly prompted the individual subjective initiative. As the result of the meaningful research and thought to complete the digital experience of creation works, the learning is no longer monotonous and students become the main focus of learning activities, which can help to a great foundation for lifelong learning.

\section{References}

[1] Na-na Liu. Study on computer teaching reform of non-computer major [J]. Heilongjiang Higher Education Research, 2006 (7) 27-31 (In Chinese).

[2] Xin Li. The influence of computer technology on graphic design industry [J]. Artistic Exploration, 2005 (4) 12-16 (In Chinese).

[3] Wen-hai He, Ming-zhu $\mathrm{Wu}$, Jiang-gang Xie. The teaching mode of the combination of EQ and IQ [J]. Modern Computer, 2007(8) 50-53 (In Chinese).

[4] Xian-feng Zhang. Visual Basic program design (project training teaching)[M]. Beijing: Mechanical Industry Press, 2008 (6) 19-23 (In Chinese).

[5] Zhi-yong Fu, Jing Yang, Lin Li, Dong-lei Liu. Computer aided design [M]. Wuhan: Hubei Arts Press, 2004, (3) 43-47 (In Chinese). 